\title{
Creative industries urban model: structure and functioning
}

Helin Liu MSc (Eng), PhD

Research Associate, Department of Land Economy, University of Cambridge, Cambridge, UK
Elisabete A. Silva PhD, FRICS, MRTPI

Senior Lecturer, Department of Land Economy, University of Cambridge, Cambridge, UK

The last decade saw the wide promotion of creative industries at city-scale development agendas. However, these practices have attached too much emphasis to investment in specific regeneration projects or flagship developments rather than addressing the nature of the infrastructure, networks and agents engaged. This paper presents an agentbased model (termed CID-USST) that was developed to explore this overlooked aspect. It uses Nanjing, a Chinese metropolis in the Yangtze River delta, as a case to illustrate how the dynamics of city-scale location behaviours of creative firms and creative workers is simulated. The model has the capability to generate different scenarios to examine the spatial distributions and spatial clustering patterns of the creative firms and creative workers, as well as the spatial distribution of the housing rent and the office rent resulting from the firms' and the workers' spatial movements.

\section{Introduction}

Creative industries' capability to promote growth in the economy and employment has been highly emphasised since its coinage (DCMS, 1998). Later, their contribution to support urban creativity (Stam et al., 2008; Scott, 2006), facilitate urban regeneration (Evans, 2005; Pratt, 2009), and promote sustainable urban development (Kakiuchi, 2012; Forum for the Future, 2010) is also highlighted. These views, together with the work by Landry (2000) on the 'creative city' and by Florida (2002) with respect to reasoning on 'creative class', indicate that in the twenty-first century, the most successful economies and societies will be the creative ones (Baum et al., 2008). Thus, the key to urban success is to attract and retain the creative talents and to cultivate the creative industries. However, much of the focus has been around the investment in specific regeneration projects or flagship developments rather than addressing the nature of the infrastructure, networks and agents engaging in the city's cultural development (Comunian, 2011). This paper describes the development of an agent-based model (ABM) in order to understand this overlooked aspect by examining the dynamics of the in-city location behaviours of the creative firms and the creative workers. This dynamics process, in essence, deals with the relationship between the creative industries' development and the urban spatial structure transformation. Thus, by taking the initials of these seven words, this model is termed a 'CID-USST' model.

This CID-USST model is developed by using NetLogo, a free programmable modelling platform which specialises in agentbased modelling (Wilensky, 1999) and now available for download at http://www.landecon.cam.ac.uk/research/lisa/lisa.html.
Table 1 depicts the basic concepts for agent-based modelling in NetLogo. As this model involves discussion of the geographical location of the agents (the firms and the workers), accordingly this CID-USST model is designed as spatially explicit. The spatial environment is a simplified urban space of Nanjing, a metropolis in the Yangtze River delta, China. The complete model provides an interface which can be easily used by people with no professional modelling knowledge or skills. By manipulating the input parameters, the user can specify a range of scenario options that reflect different urban policy schemes such as the number, the spatial allocation and the duration of policy packages. Also, the interface provides the user with the tools to set up different critical values for the triggers (that influence the locational movements of the creative firms and the creative workers) and different geographies of the simplified urban space. The outputs resulting from these different scenarios are mainly recorded by graphs (besides the visual display provided by the ABM) which describe the spatial distributions, spatial clustering patterns of the creative firms and the creative workers, and the spatial distributions of the housing rent and the office rent resulting from their spatial movements.

\section{Case and data}

The concept of 'creative industries' has its origin from 'culture industry' and is always entangled with debates on cultural policy (O'Connor, 2007). This feature indicates that the locational behaviours of the creative industries may vary from case to case, which in fact has been justified by case studies (Dainov and Sauka, 2010; Žaucer et al., 2011). In light of this, the present research is placed in the context of a Chinese city, 
Agent

Environment

\section{Spatially implicit}

Spatially explicit
'Turtle'

Set by the modeller as necessary

'World'

Table 1. Concepts for agent-based modelling in NetLogo

Nanjing. Nanjing is the capital city of the coastal province of Jiangsu, which is adjacent to the global city Shanghai. It has a population of 8.01 million and covers a land area of $6587 \mathrm{~km}^{2}$ (Nanjing Bureau of Statistics, 2011). It has a history of more than 2500 years and is abundant in cultural heritage and legacies of declining sites once used for heavy industries. Now it is striving to upgrade its economic structure and restructuring urban land-use arrangements by referring to the recipe of 'creative city' and 'creative industries'.

As the plural form 'industries' implies, creative industries include a series of sub-sectors, some of which differ significantly from each other in many aspects (Forum for the Future, 2010; Hartley, 2005). Thus, it would be misleading to draw conclusions by binding up all the creative businesses as one sector, with no inherent heterogeneity. In this research, the research object is narrowed down to two subsectors: software design and cartoon design, which are the two priority subsectors supported by the urban government of Nanjing.

The data required for model development were mainly collected by way of questionnaires and semi-structured interviews. In this process, 67 creative firms (managers or office directors), 310 creative workers, 492 citizens were investigated, respectively, by three different types of questionnaires. Two officers from the local planning bureau were also interviewed in a semi-structured style.

Analysis of the data reveals that a firm's in-city office location decision is mainly determined by eight factors, which, sorted by importance from high to low, are

- government policy guidance

- urban road transport (bus line)

- high-speed public transport (underground)

- cooperation and trade milieu among firms

- geographical proximity

- land/office rent

- sharing of talent pool

- physical environment.

In contrast, six factors determine the workers' residence location, which, in order of importance, are
- public transport (bus line and underground)

- convenience for buying daily supplies

- housing rent/price

- physical environment quality

- allocation/inheritance

- cultural facility.

The government has the incentive to support the development of the creative industries. Basically, three kinds of supportive policies are adopted
- tax reduction
- lower land/office rent
- trade/milieu promotion.

In China, the urban land is state-owned. So the urban government (on behalf of the state) has the right to define the land development rights and sometimes even has the right to expropriate land or properties to accommodate the creative firms. This practice triggers tension between the citizens and the government. However, most people $(92 \%$ of the citizens surveyed in this study through questionnaires) prefer to cooperate with the government in supporting the creative industries, if the government can offer fair compensation. So, for purposes of simplification, in the model it is supposed that the government provides satisfactory compensation in all cases and thus the interest group of the individual citizens can be left out.

\section{Structuring the dynamics in the model}

Based on the data collected above and the simplification of the interactions, three agent classes are included in this model. They are the creative firms, the creative workers and the urban government. Figure 1 is the simplified dynamics framework, which briefly describes the interaction mechanism among the three agent classes. It can be seen that the urban land is at the central position, as it serves as an intermediary to connect the three agent classes. The design is such that every land plot has a set of properties (locational marks, land-use type, terrain, usable-or-not, district, building quality). These properties change accordingly when the agents move spatially. In turn, the dynamics of the land properties exert influence upon the location decisions of the three agent classes. 


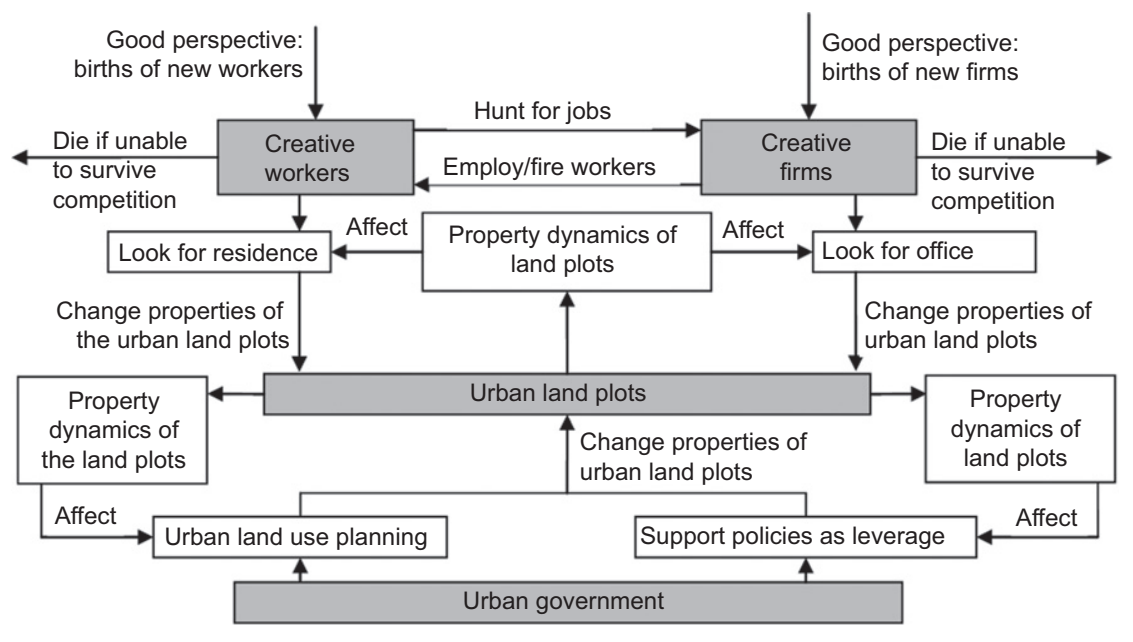

Figure 1. The simplified framework of the dynamics

The government practices its role using two approaches: supportive policies and land use planning. For the purpose of simplification, it is supposed here that the supportive policies are always adopted as leverage to promote development in certain urban areas, even though sometimes the government grants support directly to designated firms. To enforce these policies, the government first designs the policy packages (combination of the three policies). Then it allocates these packages to certain urban areas expecting to attract the influx of investment to these areas. Regarding land use planning, this refers to four aspects: urban regeneration, land expropriation for new development projects, density control, and land resource control. The plots with the lowest building quality are more likely to be renewed and those in the suburb identified by the government as profitable areas are possibly to be expropriated for new development. The government also defines the usability of each land plot. The plots defined as farmland or reserve area cannot be occupied by the firms or the workers. To avoid overexploitation, each plot is capped with a maximum plot ratio.

It is supposed that, in this framework, the creative firms and the creative workers are mutually dependent: the firms need the workers to produce service and generate profits; the workers, on the other hand, need the firms to offer jobs so as to sustain their lives. With the profits, it is possible for the firms to look for good offices; and with the payment, the workers can rent/buy residence properties fitting to their needs. Both the firms' location decision regarding the office and the workers' location decision regarding housing change the properties of the land plots and the neighbouring ones where they settle down. The changing of the land properties, as a result, possibly can affect the spatial movement of the other agents around.
During this dynamics process, it is possible that some workers cannot find suitable housing or they cannot get jobs. If this situation persists too long, these workers then will be excluded from the system. Similarly, a firm which runs out of capital or fails to find an office within a certain time will be ruled out of the system. Contrary to these agents being removed from the system (commonly, in ABM, termed agent deaths), here agent births are also allowed. The model is designed so that if the employment rate is high, new workers will join the system; and if the service demand is greater than the total supply (produced by the workers), then there will be new births of firms.

\section{Model implementation by using NetLogo}

\subsection{Setting up the input parameters}

The interface of the complete CID-USST model is illustrated by Figure 2. The 'world', the black window in the user interface (Figure 2), is used to represent the urban land space. The 'patches' are regarded as the land plots. It is regulated so that each land plot can have only one land-use type, so modelling complexity can be reduced. For this purpose, the scale is set to 1 to 10000 , which means that each patch denotes a $100 \mathrm{~m} \times 100 \mathrm{~m}$ land plot. The origin of the coordinate is exactly at the centre of this 'world'. Thus, the origin can serve as the central point of the Central Business District (CBD). The $x$ coordinate and the $y$ coordinate are set to the same maximum value of 100 . These settings result in an urban space of $400 \mathrm{~km}^{2}$. This urban space is divided into five concentric ring areas: $\mathrm{CBD}$, inner urban area, outer urban area, inner suburb and outer suburb. The boundary of each area is decided by referring to the size proportion of the corresponding area in the case of Nanjing. The time interval (tick) in this model is set 
Urban Design and Planning Volume 168 Issue DP2
Creative industries urban model:

structure and functioning

Liu and Silva

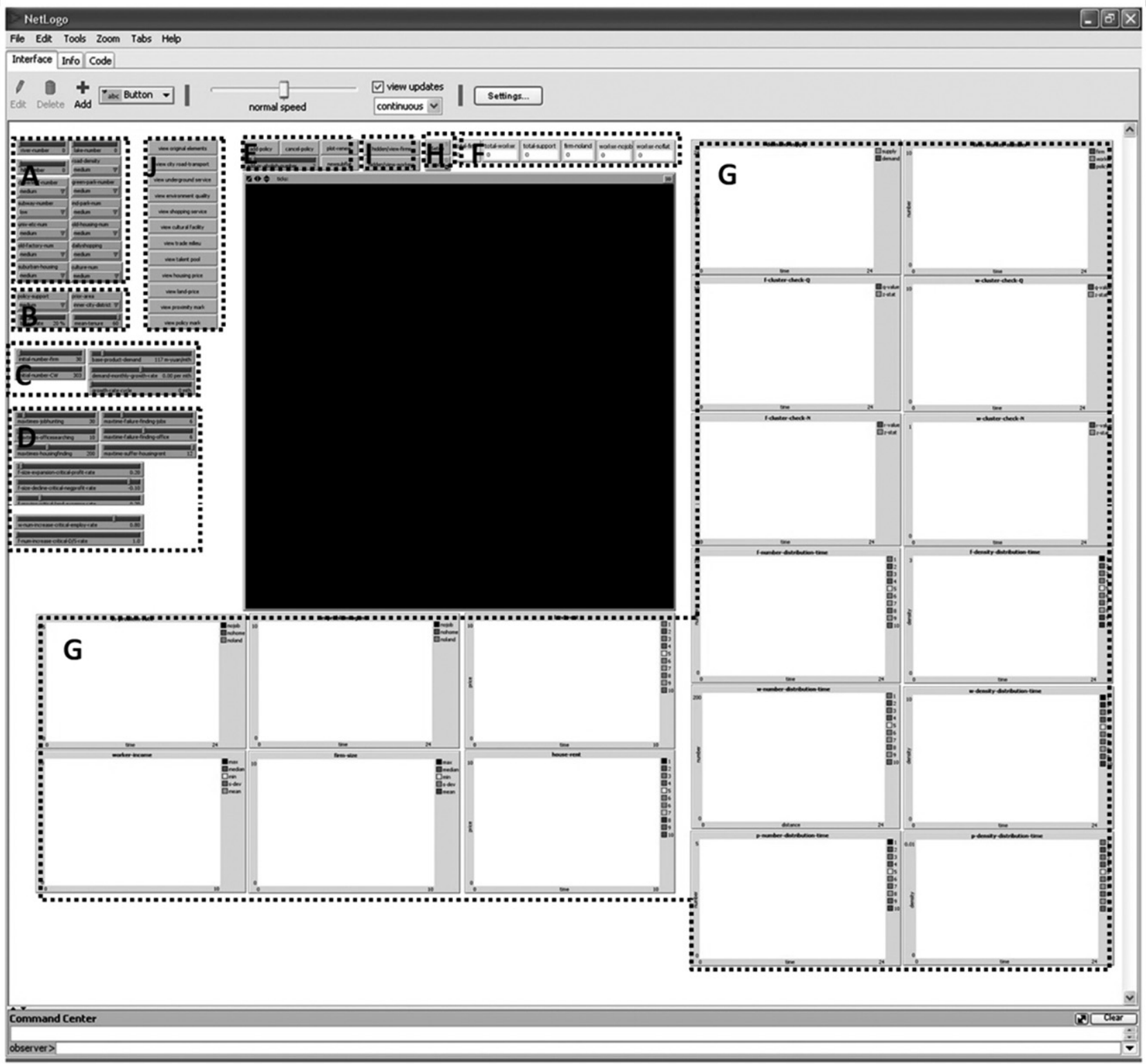

Figure 2. The user interface of the complete model

to one month, which corresponds to the real time period that the firms arrange payments and other general businesses.

As stated in the aforementioned section, each land plot has a set of properties. The value of this property set differs from plot to plot because each plot features different geographical factors and socioeconomic factors. The geographical factors are defined by section $\mathrm{A}$ in Figure 2 (Figure 3). By changing the values of these parameters, different geographies of the simplified urban space can be defined.
In contrast, section B in Figure 2 is designed for setting up the policy packages. According to the case of Nanjing, the most frequently adopted supportive policies are: tax reduction, lower land/office rent and trade/milieu promotion. In the setting-up process, these policies are repackaged and allocated to certain plots by referring to the parameters 'policy-support' and 'prior area' (Figure 4). The parameter 'b-tax-rate' means the basic income tax rate that the government generally applies to the firms. The 'mean-tenure' is the mean duration for all the policy packages. 


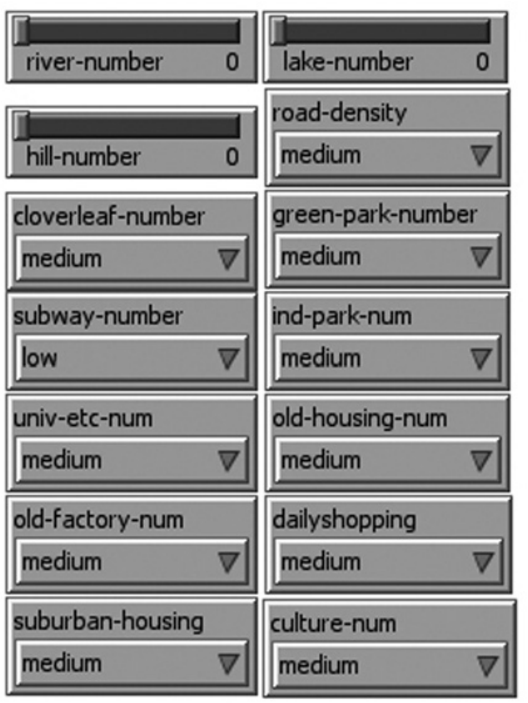

Figure 3. Section A in Figure 2: tools to set the geographical features

\begin{tabular}{|c|c|c|}
\hline \multicolumn{2}{|c|}{ policy-support } & prior-area \\
\hline medium & $\nabla$ & inner-city-district $\nabla$ \\
\hline & & {[} \\
\hline b-tax-rat & $0 \%$ & mean-tenure \\
\hline
\end{tabular}

Figure 4. Section B in Figure 2: tools to set the policy packages

Section $\mathrm{C}$ of the user interface serves as a tool for setting the numbers of the seed firms and the seed workers (Figure 5). It also provides the user the access (the two sliders on the right) to setting the initial demand (in value) of the creative production (software, cartoon and animation) per month. The parameter 'demand-monthly-growth-rate' is developed for the user to set the monthly demand increase rate. If it is set to 0 , the product demand of each month will stay steady, equal to the 'base-product-demand'. If its value is greater (smaller) than 0 , then the total product demand of each month will increase (decrease) accordingly. The 'growth-rate-cycle' is used to simulate the periodical fluctuation of the demand market of the product.

As the dynamics' framework describes, all the agent classes in the model behave following certain rules. These rules are commonly termed as 'condition-action rules' or 'triggers'. Table 2 describes all of the rules that the firms, the workers and the government (policy packages) follow in this model. These rules are closely related to the values of the parameters, as shown in Figure 6. The upper six sliders deal with the three

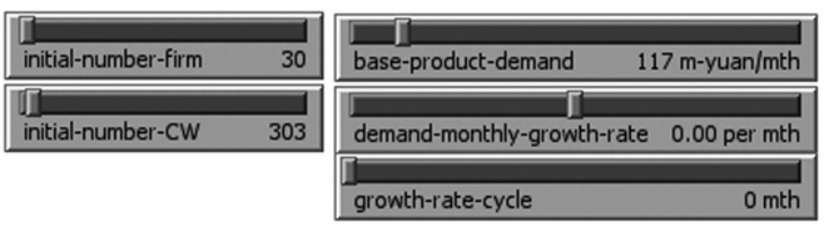

Figure 5. Section $C$ in Figure 2: tools to set the primitive number of agents and the product demand per month

actions of the agents: the workers to find jobs and to look for accommodation; the firm to look for an office. Of the middle three sliders, the first two define under which condition the firm will increase/decrease its expected size (and thus total office area). The third one is the critical value that determines at which land expense rate the firm will relocate itself. The last block consists of two sliders. Both of them are the critical values that relate to the birth of new agents (firms, workers).

\subsection{Calculating the locational marks and the office/ housing rent}

\subsubsection{Locational marks based on the influence of geographical features}

When all the input parameters are set, the user can press the 'setup' button, which will generate the corresponding geography of the urban space (Figure 7). In addition, the primitive locational marks of each land plot will also be calculated.

When calculating the locational marks, it is assumed that the influence of the geographical features on the neighbouring plots is inverse to the distance from this feature to the plots. Thus, it can be inferred that the influence fades slowly along the way to the limited distance. In this model, the influence is quantified by the following formula

$$
\text { 1. } I_{n}=\prod_{i=n}^{N}\left(1+\frac{1}{i}\right)(n=1,2,3, \ldots, N)
$$

where $I_{n}$ is the locational mark for plots in grade (area) $n$ (see Table 3 ) and $N$ is the value of the total grades (see Table 3 ).

When the calculation of $I_{n}$ of every geographical feature for each plot is complete, it is important to standardise these values. Otherwise, because of different times of multiplying for different features in the computation process, it is possible that some features could affect the calculation result more significantly than others, or even act as a dominant role. For the purpose of simplification in programming, a standardisation 


\begin{tabular}{|c|c|c|c|}
\hline Agent class & Trigger & Action & $\begin{array}{l}\text { Relevant parameters in the } \\
\text { user interface }\end{array}$ \\
\hline \multirow[t]{4}{*}{ Urban government } & There are supportive policy schemes & $\begin{array}{l}\text { Sets policy marks of the involved } \\
\text { plots }\end{array}$ & 'policy-support' (Figure 4) \\
\hline & Duration of a policy package is due & Withdraws the policy package & 'mean-tenure' (Figure 4) \\
\hline & $\begin{array}{l}\text { The land plot can be used for office } \\
\text { development or housing development }\end{array}$ & $\begin{array}{l}\text { Sets its maximum plot ratio for } \\
\text { development }\end{array}$ & $\begin{array}{l}\text { N/A (it is related to the built- } \\
\text { in variable 'land-type') }\end{array}$ \\
\hline & $\begin{array}{l}\text { There are new land use development } \\
\text { schemes }\end{array}$ & $\begin{array}{l}\text { Renew derelict sites/land } \\
\text { expropriation and develop new } \\
\text { properties }\end{array}$ & $\begin{array}{l}\text { 'plot-renew', 'newsubflat' } \\
\text { (Figure 8) }\end{array}$ \\
\hline \multirow[t]{6}{*}{ Creative firms } & $\begin{array}{l}\text { Time of failing to find the right office } \\
\text { site }>\text { the maximum times that it can } \\
\text { tolerate }\end{array}$ & Dies and is permanently excluded & $\begin{array}{l}\text { 'maxtime-failure-finding- } \\
\text { office' (Figure 6) }\end{array}$ \\
\hline & Firm's total capital $<0$ & Dies and is permanently excluded & $\begin{array}{l}\text { N/A (it is related to the built- } \\
\text { in variable 'capital') }\end{array}$ \\
\hline & $\begin{array}{l}\text { Profit rate }>\text { the critical profit rate } \\
\text { (usually positive) }\end{array}$ & $\begin{array}{l}\text { Increase firm expected size/ } \\
\text { employ workers }\end{array}$ & $\begin{array}{l}\text { 'f-size-expansion-critical- } \\
\text { profit-rate' (Figure 6) }\end{array}$ \\
\hline & $\begin{array}{l}\text { Profit rate }<\text { the critical profit rate } \\
\text { (usually negative) }\end{array}$ & $\begin{array}{l}\text { Decrease firm expected size/fire } \\
\text { workers }\end{array}$ & $\begin{array}{l}\text { 'f-size-decline-critical- } \\
\text { negprofit-rate' (Figure 6) }\end{array}$ \\
\hline & $\begin{array}{l}\text { The rate of land expense to the sales } \\
\text { value }>\text { the critical land expense rate }\end{array}$ & Relocate the office & $\begin{array}{l}\text { 'f-moving-critical-land- } \\
\text { expense-rate' (Figure 6) }\end{array}$ \\
\hline & $\begin{array}{l}\text { The rate of demand to supply }>\text { the } \\
\text { critical rate }\end{array}$ & Birth of new firms & $\begin{array}{l}\text { 'base-product-demand', } \\
\text { 'demand-monthly-growth- } \\
\text { rate', 'growth-rate-cycle', } \\
\text { 'f-num-increase-critical-D/S- } \\
\text { rate' (Figure 6) }\end{array}$ \\
\hline \multirow[t]{4}{*}{ Creative workers } & $\begin{array}{l}\text { Times of failing to find a job in the } \\
\text { creative firms }>\text { the maximum times } \\
\text { he can endure }\end{array}$ & Dies and is permanently excluded & $\begin{array}{l}\text { 'maxtime-failure-finding- } \\
\text { jobs' (Figure 6) }\end{array}$ \\
\hline & $\begin{array}{l}\text { Times of failing to find a place to live }> \\
\text { the maximum times he can endure }\end{array}$ & Dies and is permanently excluded & $\begin{array}{l}\text { 'maxtime-suffer-housingrent' } \\
\text { (Figure 6) }\end{array}$ \\
\hline & Housing rent $>$ half the income & Move to another cheaper site & $\begin{array}{l}\text { N/A (it is related to the built- } \\
\text { in variable 'real-income') }\end{array}$ \\
\hline & $\begin{array}{l}\text { Employment rate }>\text { the critical } \\
\text { employment rate }\end{array}$ & Birth of new workers & $\begin{array}{l}\text { 'w-num-increase-critical- } \\
\text { employ-rate' (Figure 6) }\end{array}$ \\
\hline
\end{tabular}

Table 2. Triggers and action rules for the three agent classes

formula is used, as shown below

2. $S M_{i j}=1+\frac{M_{i j}-1}{\max \left(M_{i}\right)-1}$

where $S M_{i j}$ is the standardised locational mark of feature $i$ on plot $j ; M_{i j}$ is the locational mark of plot $j$ which is calculated by Equation 1; and $M_{i}$ is the set of the locational mark of feature $i$ on all the land plots.

\subsubsection{Base land-rent and housing-rent}

For each plot, both the base land-rent and housing-rent are calculated. The rent means the amount of money a firm (or a worker) must pay for $1 \mathrm{~m}^{2}$ of office (housing) area every month. The formula for calculating the initial land-rent is the same as that for calculating the primitive housing-rent of each land plot (patch). It can be expressed by

3. $R=A * \sum_{i=1}^{N}\left(S M_{i} *\left(N-O_{i}\right)\right)$

where $R$ is the office rent or housing rent on this plot; $S M_{i}$ is the standardised primitive locational mark derived from locational factor $i$ on this plot; $O_{i}$ is the importance order that the firms or the workers think of locational factor $i$; $A$ is the price constant, which can be decided by referring to the case 

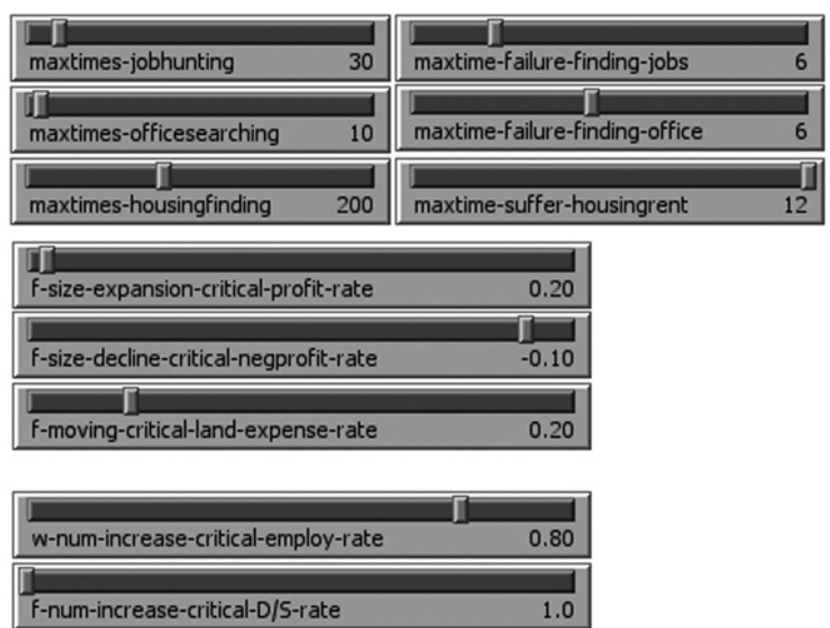

Figure 6. Section D in Figure 2: tools to set the critical values (triggers) for the firms and the workers

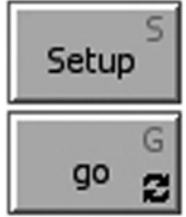

Figure 7. Section $\mathrm{H}$ in Figure 2: the 'setup' and the 'go' buttons

study (in the present case of Nanjing, it is 3.5 for the firms, and for the workers it is 2.5); and $N$ is the total number of locational factors that decide the location decision of the firms and the workers. $N$ is 8 for the firms and 5 for the workers. (Note: as described earlier, eight factors determine the firms' location decisions and six factors define the workers' location decisions. However, within the six factors for the workers, the factor 'allocation/inheritance' is directly related to personal situation, which is dealt with separately in the model. Thus it is not included in this calculation.)

\subsection{Model dynamics}

Only when the 'setup' procedure is complete can the model execute the dynamics process, which can be initiated by pressing the 'go' button in section $\mathrm{H}$ of the user interface (Figure 7). The three agent classes then will repeat their behaviours according to the preset condition-action rules (Table 2). This section presents more details about the operation of the model in terms of dynamics.

\subsubsection{The creative firms}

\subsubsection{THE PRINCIPLE OF DECIDING WHERE TO SETTLE DOWN THE OFFICE}

In this CID-USST model, the firms without offices must try to find the right office to operate. It is supposed that they always choose the plot which can produce the highest location utility among the candidate plots (targeted plots).

To illustrate this principle, for each land plot, assume the marks for the eight factors (in order) that determine the location decision of the firms are $\left\{m f_{1}, m f_{2}, m f_{3}, m f_{4}, m f_{5}, m f_{6}\right.$, $\left.m f_{7}, m f_{8}\right\}$; for a certain firm, assume the importance indices it puts to the eight factors are $\left\{w_{1}, w_{2}, w_{3}, w_{4}, w_{5}, w_{6}, w_{7}, w_{8}\right\}$. Then, the location utility each plot can generate for this firm can be calculated by

$$
\text { 4. } \begin{array}{r}
U_{\mathrm{f}}=\left(w_{1} \times m f_{1}+w_{2} \times m f_{2}+w_{3} \times m f_{3}\right. \\
\left.+\cdots+w_{8} \times m f_{8}\right) \times Q
\end{array}
$$

\begin{tabular}{llll}
\hline Name & Variable & Related geographical features & Influence range/Total grade $(\mathrm{N})$ \\
\hline Road mark & transport-mark & Road system & $1 \mathrm{~km} / 5$ \\
Underground mark & rapidtrans-mark & Underground system & $1 \mathrm{~km} / 5$ \\
Environment mark & environment-mark & River, lake, hill, public green & $1 \mathrm{~km} / 5$ \\
Shopping mark & shopping-mark & Shopping mall & $1.6 \mathrm{~km} / 8$ \\
Culture mark & culture-mark & Cultural facilities & $0 \cdot 6 \mathrm{~km} / 6$ \\
Trade milieu mark & milieu-mark & Industrial park, policy support & $0.4 \mathrm{~km} / 4$ \\
Talent mark & talent-mark & University, industrial park & $0 \cdot 5 \mathrm{~km} / 5$ \\
Proximity mark & proximity-mark & Number of firms nearby & $\mathrm{N} / \mathrm{A}$ \\
Mark based on area & basic-mark & Sub-area the plot belongs to & $\mathrm{N} / \mathrm{A}$ \\
Land rent mark & land-rent & Locational factors firms care & $\mathrm{N} / \mathrm{A}$ \\
Housing rent mark & housing-rent & Locational factors workers care & $\mathrm{N} / \mathrm{A}$
\end{tabular}

Table 3. The influence range and grade of the geographical features 
Creative industries urban model:

structure and functioning

Liu and Silva

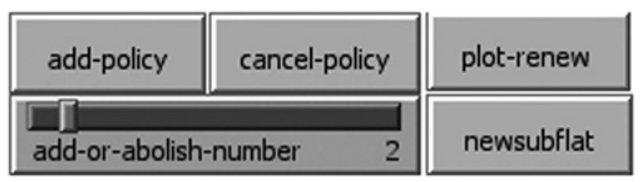

Figure 8. Section E of Figure 2: tools for the user to act as the urban government

where $Q$ is the building quality of this plot. Then the plot where this firm finally settles down can be defined as:

$$
P_{\text {final }}=P_{\max }
$$

where $P_{\max }$ satisfies that

$$
U_{\mathrm{f}}\left(P_{\max }\right)=\max \left\{U_{\mathrm{f}}\left(P_{i}\right), i=1,2,3, \ldots, m\right\}
$$

where $P_{i}$ represents land plot $i ; i$ is the number of candidate land plot, which is equal to the value of 'maxtimesofficesearching' (Figure 6).

\subsubsection{THE CREATIVE FIRM'S INFLUENCE UPON THE PLOTS INVOLVED}

As mentioned earlier, both a firm's 'moving in' and 'moving out' will affect the value of the locational marks of the neighbouring plots. This effect is described by two variables: influence grade and range, and rate (Table 4). It is difficult to quantify the influence on the locational marks, so the 'trial-and-error method' is adopted. First the influence range and grade is estimated. Then different rates are tried, checking the maximum increasing/decreasing times that this plot (which the firm moves into/out of) might have. By comparing the macro effect with the case of Nanjing, the final values were set as detailed in Table 4.

By referring to this table, the variation index of a firm's moving-in or moving-out can be calculated be way of
Equation 5, as given below

5. $\quad V_{n(\text { firm })}=r_{(\text {firm })}^{N-n}(n=1,2,3, \ldots, N)$

where $V_{n \text { (firm) }}$ is the variation (decreasing/increasing) index for the plots in grade (area) $n$; $r_{\text {(firm) }}$ is the basic influence rate by a firm; and $N$ is the value of the total grades.

When this index is readily calculated, it is possible then to calculate the updated locational marks of each involved land plot using Equation 6

6. $L M_{i(\text { new })}=\left\{\begin{array}{l}L M_{i(\text { old })} \times V_{i(\text { firm })} \text { if a firm is moving in } \\ L M_{i(\text { old })} / V_{i(\text { firm })} \text { if a firm is moving out }\end{array}\right.$

where $L M_{i(\text { new })}$ is the updated locational marks for factor $i$; $L M_{i(\mathrm{old})}$ is the original locational marks for factor $i$; and $V_{i \text { (firm) }}$ is the variation index calculated by Equation 5 .

\subsubsection{The creative workers}

\subsubsection{THE PRINCIPLE OF DECIDING WHERE TO LIVE}

Comparing with the firms, the workers also follow the same principle of deciding where to live. That is to maximise the location utility in terms of residence. Assume that the marks that a plot features for the five factors appreciated by a firm are $\left\{m w_{1}, m w_{2}, m w_{3}, m w_{4}, m w_{5}\right\}$, and the importance indices this firm puts to the five factors are $\left\{w_{1}, w_{2}, w_{3}, w_{4}, w_{5}\right\}$. Then the location utility this plot can generate for this worker is

$$
\text { 7. } U_{w}=\left(\begin{array}{c}
w_{1} \\
\times m w_{1}+w_{2} \times m w_{2}+w_{3} \times m w_{3} \\
\left.+\cdots+w_{5} \times m w_{5}\right) \times Q
\end{array}\right.
$$

\begin{tabular}{|c|c|c|c|c|c|}
\hline \multirow[b]{2}{*}{ Object } & \multirow[b]{2}{*}{ Influenced variable } & \multirow{2}{*}{$\begin{array}{l}\text { Influence grade }(N) \\
\text { and range }(n) \text { (the } \\
\text { unit is one patch) }\end{array}$} & \multirow[b]{2}{*}{ Rate $(r)$} & \multicolumn{2}{|c|}{ Macro effect (variation times) } \\
\hline & & & & If ten firms move in/out & If 20 firms move in/out \\
\hline Building quality & building-quality & 3 grades $\{0,1,2\}$ & $1 \cdot 01$ & $1 \cdot 35$ & $1 \cdot 82$ \\
\hline Land rent & land-rent & 3 grades $\{0,1,2\}$ & 1.01 & $1 \cdot 35$ & $1 \cdot 82$ \\
\hline Proximity & proximity-mark & 3 grades $\{0,1,2\}$ & $1 \cdot 01$ & $1 \cdot 35$ & $1 \cdot 82$ \\
\hline Trade milieu & milieu-mark & 2 grades $\{0,1\}$ & $1 \cdot 01$ & $1 \cdot 22$ & 1.49 \\
\hline Real volume & f-real-volume & N/A & N/A & $+10 \times$ expected size & $+20 \times$ expected size \\
\hline
\end{tabular}

where $Q$ is the building quality of this plot.

Thus the residence location for this firm is identified by

$$
P_{\text {final }}=P_{\max }
$$


where $P_{\max }$ satisfies that

$$
U_{w}\left(P_{\max }\right)=\max \left\{U_{w}\left(P_{i}\right), i=1,2,3, \ldots, m\right\}
$$

where $P_{i}$ represents land plot $i$ and $i$ is the number of candidate land plot which is equal to the value of 'maxtimeshousingfinding' (Figure 6).

\subsubsection{THE CREATIVE WORKER'S INFLUENCE UPON THE PLOTS INVOLVED}

Following the same principle, it is assumed that the worker's moving-in or moving-out can also have an impact on the locational properties of the involved plots. Generally, the worker cannot improve the urban road system directly. In this model, it is assumed that the concentration of creative workers in a certain site can prompt the government to improve the bus services, and massive moving-out can result in removing of some bus lines. The influence is described as shown in Table 5 .

Based on this table, similarly the updated locational marks of each involved land plot are calculated by Equations 8 and 9

8. $\quad V_{n(\text { worker })}=r_{\text {worker }}^{N-n}(n=1,2,3, \ldots, N)$

where $V_{n \text { (worker) }}$ is the variation (decreasing/increasing) index for the plots in grade (area) $n ; r_{\text {(worker) }}$ is the basic influence rate by a worker; and $N$ is the total number of grades.

9. $L M_{i(\text { new })}=\left\{\begin{array}{l}L M_{i(\text { old })} \times V_{i(\text { worker })} \text { if a worker is moving in } \\ L M_{i(\text { old })} / V_{i(\text { worker })} \text { if a worker is moving out }\end{array}\right.$

where $L M_{i \text { (new) }}$ denotes the updated locational marks for factor $i$; $L M_{i \text { (old) }}$ represents the original locational marks for factor $i$; and $V_{i \text { (worker) }}$ is the variation index calculated by Equation 9 .

\subsubsection{The urban government}

At the setting-up stage, the user can change the values of the parameters in section B of the user interface (Figure 4) to define the policy schemes. During the running of the model, the user can still act as urban government by using the tools provided by section E (Figure 8) to enforce new supportive policy schemes or urban land-use planning schemes. Through these tools, the user can add/cancel policy packages or start new regeneration/ development projects and in this way test different scenarios. The button 'plot-renew' points to the procedure of urban regeneration. Once it is pressed during the operation of the model, a set of plots with lower building quality (building quality $<0.5$ ) will be randomly selected out and renewed. If necessary, the user can also change the previously protected areas (such as the farmland) into entry-permitted land plots and develop new housing properties on them by pressing the button 'newsubflat'.

\subsection{Model output-display}

Once the model starts to run it is possible to display the simulation results. These results are spatially visible in the 'world' by swapping views by way of sections I and $\mathbf{J}$ of the user interface (Figures 9-11).

Section F consists of six monitors (Figure 2). The first three are used to record the total number of firms, the total number of workers and the total number of policy packages that the government provides. The last three, in contrast, are developed to report the number of firms without office, workers with no job and workers with no suitable accommodation (Figure 12).

In section $G$ (Figure 13), at the top right, the first two plots are used to record the basic feature of the whole system: the supply-demand relationship, and the number of each agent class. In the middle, following these two plots are tools to examine the spatial clustering pattern of the creative workers and the creative firms. For this purpose, two spatial statistics are used (Wong and Lee, 2005). One is the variance-mean ratio (VMR) by the method of quadrat analysis, which is used by plots 'f-cluster-check-Q' and 'w-cluster-check-Q'. The

\begin{tabular}{|c|c|c|c|c|c|}
\hline \multirow[b]{2}{*}{ Object } & \multirow[b]{2}{*}{ Influenced variable } & \multirow[b]{2}{*}{$\begin{array}{l}\text { Grade }(N) \text { and range }(n) \\
\text { (the unit is one patch) }\end{array}$} & \multirow[b]{2}{*}{ Rate $(r)$} & \multicolumn{2}{|c|}{ Macro effect (variation times) } \\
\hline & & & & $\begin{array}{c}\text { if } 100 \text { workers move } \\
\text { in/out }\end{array}$ & $\begin{array}{c}\text { if } 200 \text { workers move } \\
\text { in/out }\end{array}$ \\
\hline Building quality & building-quality & 3 grades $\{0,1,2\}$ & $1 \cdot 002$ & 1.82 & $3 \cdot 32$ \\
\hline Housing rent & w-housing-rent & 2 grades $\{0,1\}$ & $1 \cdot 002$ & $1 \cdot 49$ & $2 \cdot 22$ \\
\hline Talent mark & talent-mark & 5 grades $\{0,2,4,6,8\}$ & $1 \cdot 001$ & $1 \cdot 65$ & $2 \cdot 72$ \\
\hline Transport mark & transport-mark & 3 grades $\{0,4,8\}$ & $1 \cdot 002$ & $1 \cdot 82$ & $3 \cdot 32$ \\
\hline Real volume & w-real-volume & N/A & N/A & $+100 \times$ housing size & $+200 \times$ housing size \\
\hline
\end{tabular}

Table 5. The influence upon environmental variables caused by workers 
Urban Design and Planning Volume 168 Issue DP2
Creative industries urban model: structure and functioning

Liu and Silva

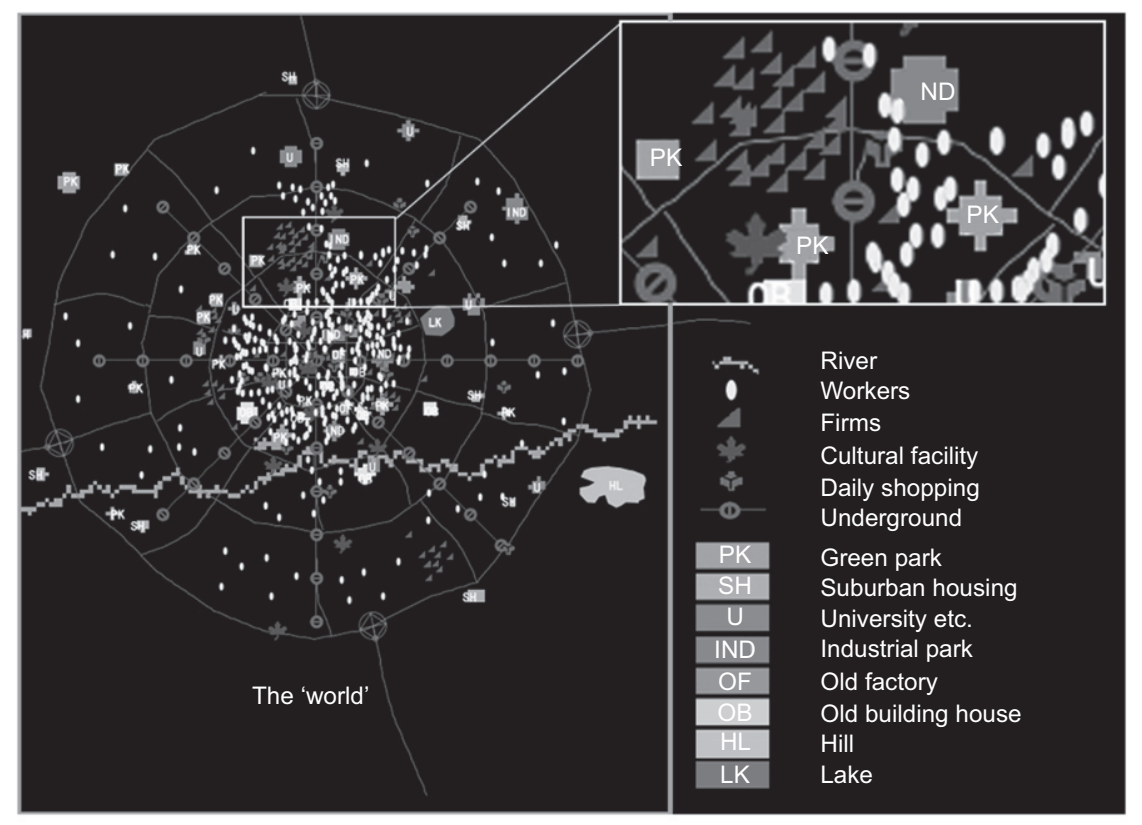

Figure 9. The 'world' as direct demonstration medium of the results

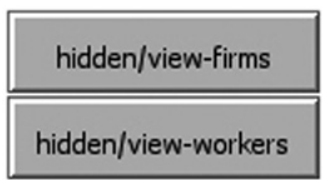

Figure 10. Section I of Figure 2: tools to show/hide the two agent classes (creative firms, creative workers)

expression for VMR is

$$
\text { 10. } \quad \mathrm{VMR}=\frac{S^{2}}{\bar{X}}
$$

where $S^{2}$ is the deviation of the point number of all the quadrats and $\bar{X}$ is the average point number of all the quadrats.

The other is the $R$ statistic by nearest neighbour analysis. It is adopted by the other two plots ('f-cluster-check-N' and 'w-cluster-check-N'). The expression is

11. $R=\frac{R_{\mathrm{o}}}{R_{\mathrm{e}}}=\frac{\sum d_{i} / n}{0.5 \sqrt{A / n}}$

where $d_{i}$ is the nearest distance of each point, $A$ is the study area and $n$ is the number of points.

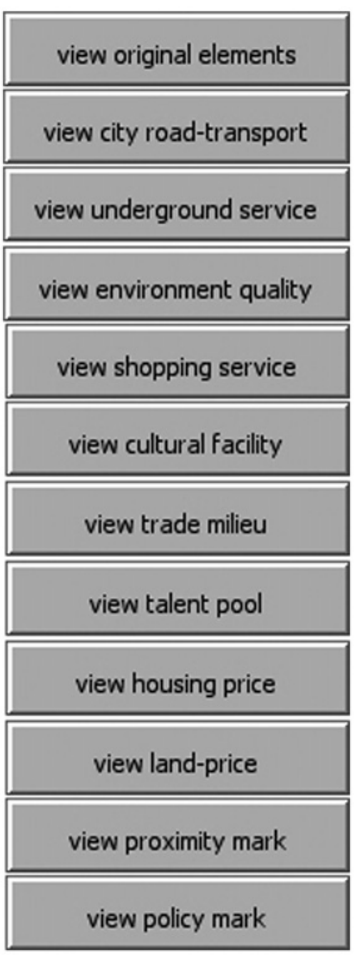

Figure 11. Section J of Figure 2: tools to show the spatial distribution of the locational marks 


\begin{tabular}{|l|l|l|l|l|l|}
\hline total-firm & total-worker & total-support & firm-noland & worker-nojob & worker-noflat \\
\hline 0 & 0 & 0 & 0 \\
\hline
\end{tabular}

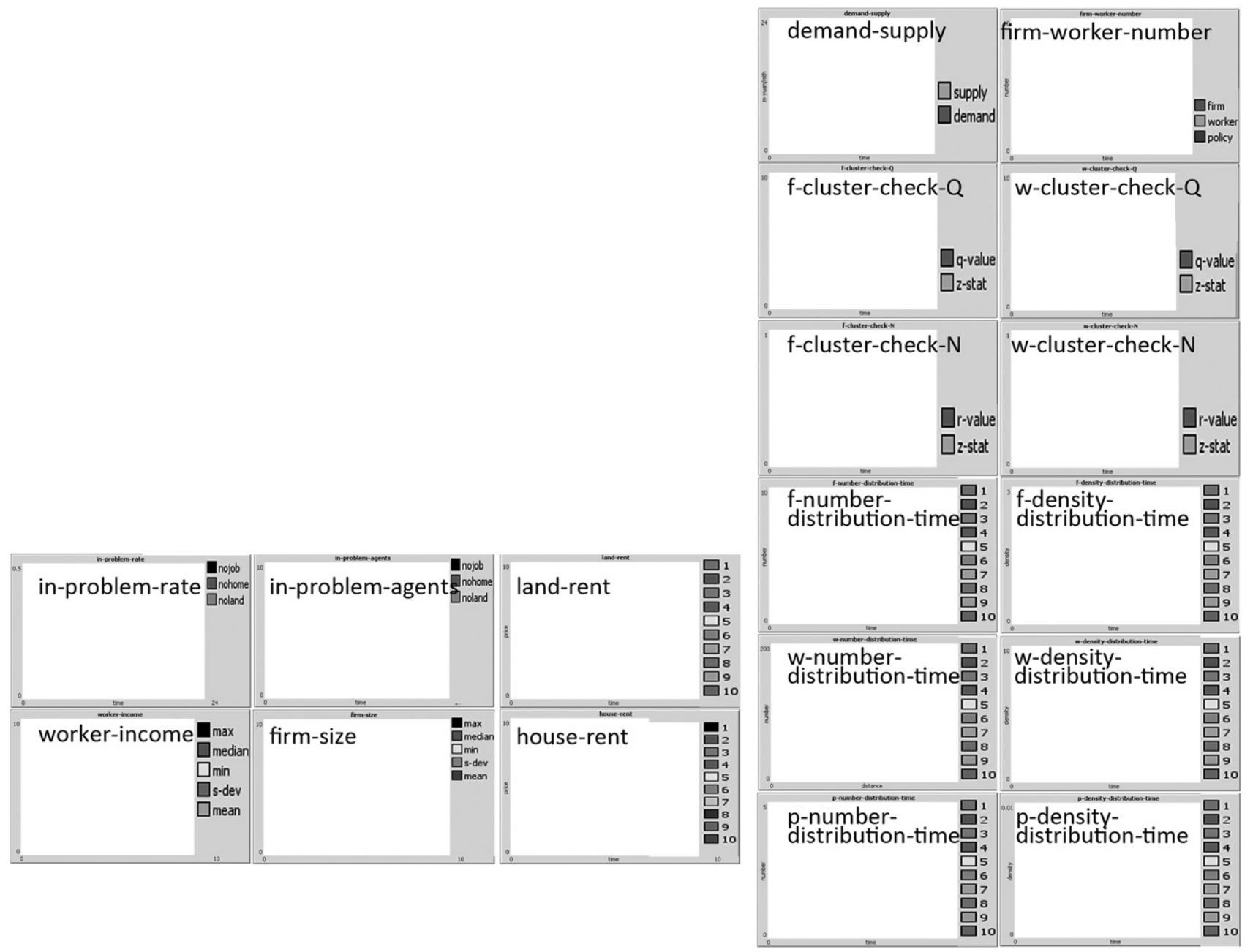

Figure 13. Section $\mathrm{G}$ in Figure 2: plots to describe the spatial distribution features and the socioeconomic features of the dynamics process

The six plots with ten labels on the legend at the bottom right are intended to report the spatial distribution of the creative workers, the creative firms and the policy packages. Of the six plots, the left three examine the total number of each agent class in different areas. The right three, in contrast, focus on the distribution density of each agent class in different areas.
Of the six plots on the left of Figure 13, the left-most four are used to record the number of agents in trouble (such as with no jobs, with no housing, or with no office) and the relative percentages. The right-most two, as displayed by the graph titles, are adopted as a medium to display the spatial dynamics of the housing rent and the office rent over time. 
Creative industries urban model:

structure and functioning

Liu and Silva

\section{Applications and further development}

This paper has presented an introduction to the CIS-USST ABM model, focusing on how it operates and how the user can employ it. It is publicly available on the website at http:/ www.landecon.cam.ac.uk/research/lisa/lisa.html. Users can download a simplified version of the model (code file based on Windows XP) and run it by using NetLogo. (The installation package is available at http://ccl.northwestern.edu/netlogo/.) A complete version of the model is also available upon direct request to the authors. Although the step of model validation has not been mentioned, the model explained above has already been validated against the case of Nanjing and the values for the built-in variables presented here are already calibrated. Thus, it can be used directly to understand the dynamics of the in-city location behaviours of creative firms and creative workers in Nanjing.

Although advanced versions of this model are being developed by the authors, the CID-USST model as described here can also be applied to other cities. Three aspects must be checked, however. First, this model only applies to single-centred cities (only one CBD). Second, the locational factors that determine the location behaviours of the firms and the workers must be adjusted accordingly. This is because the in-city location decisions of the creative firms and creative workers vary tremendously in different cases (Dainov and Sauka, 2010). Third, if necessary, a new agent class might need to be included in the dynamics framework. In countries where the land is privately owned, the government can still regulate urban development by way of land-use planning and support policies. Unlike the case in China, however, they have no rights to demolish properties, expropriate land and develop other businesses without agreement from the land owners. Thus, in order to acquire land, firms have to negotiate with the land owners (citizens) but not the government. This poses the necessity to include another agent class, the land owners, in the dynamics framework, which entails the inclusion of the mechanism of land price bargaining.

The model presented in this paper is based on a simplified abstract urban space; it can only provide general conclusions on the development of creative industries and policy suggestions regarding land-use arrangement for creative industries. For instance, questions that can be answered by using this model include the following.

(a) What are the size development patterns of the creative firms through time?

(b) Which urban area is more likely to incubate creative industries, the suburban area or the inner urban area?

(c) What kinds of policies (such as tax reduction, product exhibition events, and so on) are more effective to promote creative industries and what timeline for these policies will produce better outcomes? (d) In order to generate economic growth and employment opportunities in urban areas through creative industries, it is important to consider: what kind of policy needs to be applied and where should these policies be allocated so that these practices can produce the expected outcome?

To further enhance the applicability of this model in planning, it is important to include a spatially explicit map. By doing so, the locations of the firms and the workers can be clearly identified and the spatial allocations of all the introduced policies can be precisely specified within the studied city. To do so, first minor adaption of the dynamics' mechanism in respect of the local context is required (as stated above). Then, by replacing the abstract urban space with the real map of the city in question, the model can be used to conduct customised scenario analysis by referring to the central questions/issues that the local government considers important in the development of creative industries and the overall arrangement of urban land use.

With this aim, a customised version has already been developed to help the local government to decide the optimal land arrangement and spatial policy allocation for the development of creative industries in Jiading, a district in Shanghai, China. By importing the real map (ArcGIS shape file) of Jiading (a corresponding change of relevant algorithm had to be made in order to include a shape file), the initial real locations of the creative firms and creative workers are accurately geo-coded in the model. With the application of the improved model, the hottest spots for the creative firms and the creative workers are uncovered. Through these results, the government can clearly see the optimal sites for the firms and for the workers respectively so that they can initiate office refurbishment/construction projects and real estate refurbishment/development projects accordingly. In addition, by studying the evolution of land-use transformation displayed by the model, areas not productive to invest are easily identified. The previous analyses provide clues for the government to customise regulatory measures (policies and land use arrangements) to be applied to these sites. Also, by comparing the outcomes based on different policy scenarios (policies suggested by workshop discussion), the suitable policy packages and their spatial allocations for certain development aims are clarified, which can be regarded as the optimum development recipe that is locally tailored to each particular case study.

A further integration development is a deeper integration of the two systems (geographic information system (GIS) and ABM system). To do this, three possible options are available.

(a) Set GIS software as the dominant programming platform, using self-developed scripts or built-in agent-based modelling modules to exploit the simulation ability of ABM software. 
(b) Set ABM software as the dominant modelling platform, using the readily developed toolkits (or developing a task-oriented toolkit by oneself) to take advantage of the functions built in to GIS.

(c) By referring to the research objectives, develop a third program module which makes use of the commands and functionalities available within both systems.

Despite these promising possibilities, it is still a challenge as issues remain to be confronted, such as data structure incompatibility (between the ABM system and GIS) and data interoperability (Crooks and Castle, 2012; Heywood et al., 2011; Westervelt, 2002).

\section{REFERENCES}

Baum S, Yigitcanlar T and O'Connor K (2008) Creative industries and the urban hierarchy: the postion of lower tier cities in the knowledge economy. In Knowledge-based Urban Development: Planning and Applications in the Information Era (Yigitcanlar T, Velibeyoglu K and Baum S (eds)). Information Science Reference, Hershey, PA, USA and London, UK.

Comunian R (2011) Rethinking the creative city: the role of complexity, networks and interactions in the urban creative economy. Urban Studies 48(6): 1157-1179.

Crooks AT and Castle CJE (2012) The integration of agent-based modelling and geographical information for geospatial simulation. In Agent-based Models of Geographical Systems (Heppenstall AJ, Crooks AT and Batty LMM (eds)). Springer, London, UK.

Dainov E and Sauka A (2010) Managers and entrepreneurs in creative and knowledge-intensive industries: what determines their location? Toulouse, Helsinki, Budapest, Riga and Sofia. In Making Competitive Cities (Musterd S and Murie A (eds)). Wiley-Blackwell, Oxford, UK.

DCMS (1998) Creative Industries Mapping Document. London, UK, DCMS.

Evans G (2005) Measure for measure: evaluating the evidence of culture's contribution to regeneration. Urban Studies $\mathbf{4 2}$ (5/6): 1-25.

Florida R (2002) The Rise of the Creative Class: and How It's Transforming Work, Leisure, Community and Everyday Life. Basic Books, New York, USA.

Forum for the Future (2010) Can the Creative Industries Lead Us to a Sustainable Future? Forum for the Future, and Creative Industries Knowledge Transfer Network (CIKTN) team, see http://www.forumforthefuture.org/sites/default/ files/project/downloads/sustainability-baseline-reviewciktn-08-10-2010.pdf (accessed 16/05/2013).

Hartley J (2005) Creative Industries. Blackwell. Oxford, UK. Heywood DI, Cornelius S and Carver S (2011) An Introduction to Geographical Information Systems. Prentice Hall, Harlow, UK.

Kakiuchi E (2012) Sustainable cities with creativity: promoting creative urban initiatives - theory and practice in Japan.
In Sustainable City and Creativity: Promoting Creative Urban Initiatives (Girard LF, Baycan T and Nijkamp P (eds)). Ashgate, Farnham, UK.

Landry C (2000) The Creative City: A Toolkit for Urban Innovators. Earthscan Publications, London, UK.

Nanjing Bureau of Statistics (2011) Nanjing Statistical Yearbook 2011. Nanjing Bureau of Statistics, Nanjing, China.see http://www.njtj.gov.cn/2004/index.html (accessed 10/11/2012).

O'Connor J (2007) The Cultural and Creative Industries: A Review of the Literature. Creative Partnerships, London, UK.

Pratt AC (2009) Urban regeneration: From the arts 'feel good' factor to the cultural economy: A case study of Hoxton, London. Urban Studies 46(5/6): 1041-1061.

Scott AJ (2006) Entrepreneurship, innovation and industrial development: geography and the creative field revisited. Small Business Economics 24(1): 1-24.

Stam E, De Jong JPJ and Marlet G (2008) Creative industries in the Netherlands: Structure, development, innovativeness and effects on urban growth. Geografiska Annaler: Series B, Human Geography 90(2): 119-132.

Westervelt JD (2002) Geographic information systems and agent-based modelling. In Integrating Geographic Information Systems and Agent-based Modelling Techniques for Simulating Social and Ecological Processes (Gimblett HR (ed.)). Oxford University Press, Oxford, UK.

Wilensky U (1999) NetLogo. Center for Connected Learning and Computer-Based Modeling, Northwestern University, Evanston, IL, USA, see http://ccl.northwestern.edu/ netlogo/ (accessed 06/02/2013).

Wong DWS and Lee J (2005) Statistical Analysis of Geographic Information: with ArcView GIS and ArcGIS. John Wiley, Hoboken, NJ, USA.

Žaucer T, Uršič M, Očkerl P, Marn T and Peterlin M (2011) Potentials of Creative Urban Regeneration: Spatial Distribution of Creative Industries in Ljubljana Urban Region. Institute for Spatial Policies, Ljubljana, Slovenia.

\section{WHAT DO YOU THINK?}

To discuss this paper, please email up to 500 words to the editor at journals@ice.org.uk. Your contribution will be forwarded to the author(s) for a reply and, if considered appropriate by the editorial panel, will be published as discussion in a future issue of the journal.

Proceedings journals rely entirely on contributions sent in by civil engineering professionals, academics and students. Papers should be 2000-5000 words long (briefing papers should be 1000-2000 words long), with adequate illustrations and references. You can submit your paper online via www.icevirtuallibrary.com/content/journals, where you will also find detailed author guidelines. 